\title{
Fabrication of Lab Scale Greywater Filtration Plant for Water Management in Quetta, Pakistan
}

\author{
Zahid Naeem Qaisrania ${ }^{\mathrm{a}, \mathrm{b},}$ Asadullah ${ }^{\mathrm{a}^{*}}$, Saood Ali Shah ${ }^{\mathrm{a}}$, Narissara Nuthamachot ${ }^{\mathrm{b}}$, Kuaanan $^{\text {Techato }}{ }^{\mathrm{b}}$ \\ Pankaj kumar Jha ${ }^{\mathrm{b}}$ \\ a Department of Chemical Engineering, Balochistan University of Information Technology, Engineering \\ and Management Sciences Quetta, 87300, Pakistan \\ ${ }^{\mathrm{b}}$ Faculty of Environmental Management, Prince of Songkla University, Hatyai Campus, 90112, Hatyai, \\ Thailand \\ *Corresponding author: $\underline{\text { asad1562000@yahoo.com }}$
}

\begin{abstract}
Fresh water scarcity is one the serious environmental issues today. Depleting water resources as a result of various natural environmental and man-made factors including less precipitation, over exploitation, climate change, global warming, urbanization and many more create challenges for policy makers, governments, scientists, water resource managers and other stakeholders. Quetta is the capital city of Balochistan province of Pakistan and located in arid region with highest annual population growth rate of $5.83 \%$. The current study investigates fabrication of a lab scale greywater filtration plant for sustainable water management in Quetta. As greywater recycling is cheaper, easy to handle and sustainable method to overcome the water scarcity issue; therefore, a well-designed lab scale pilot plant has been fabricated to recycle greywater from domestic sources including kitchen, bathroom, laundry and car wash stations. Deduction competence of pollutants as total suspended solids (TSS), total dissolved solids (TDS), turbidity, pH, hardness and oil are $80 \%, 32.31 \%, 98.54 \%$, increase from 6.9 to $8.6,62.69 \%$ and $48.15 \%$ have been noted respectively.
\end{abstract}

Key words-- Quetta; Water scarcity; Grey water recycling; Fabrication

Date Received 22 Aug 2019

Date Accepted 30 Sep 2019

Date Published 25 June 2020

\section{INTRODUCTION}

Water is life, but increasing gap between demand and supply is a serious challenge for governments, public, engineers, environmentalists and other stakeholders in many parts of the world. Pakistan is also severely affected by water shortage. Balochistan is the largest province of Pakistan covering an area of $347,190 \mathrm{~km}^{2}$ and one of the most water stressed areas. Its capital city, Quetta is located between $30.18^{\circ} \mathrm{N}$ and $66.97^{\circ} \mathrm{E}$ and its climate is arid where mean annual rainfall is $244 \mathrm{~mm}$ with a huge population of 2,275,699 people [1] face severe water scarcity in current years Journal of Applied and Emerging Sciences Vol (10), Issue (01)
[2]. According to Census 2017, Quetta's annual population growth is highest among all districts of Pakistan which is $5.83 \%$. Fresh and adequate water availability is not only important for drinking and other domestic needs, but is directly related to food security and social welfare too [3]. Major source of water in Quetta for domestic and agriculture purposes is ground water which is declining rapidly [4]. This alarming situation forces residents either to migrate or to buy water or fetch from far away which has adverse impacts on economy, health and time. Mostly, people use water from tankers which is very expensive on daily basis and also has adverse health impacts. In 
current years, research on alternative sources such as wastewater treatment [5] [6] [7], desalination [8], rain water harvesting [9], surface water filtration [10] and others seem a good initiative to overcome water shortage. Greywater reuse is a globally recognized cost-effective and environment friendly practice for managing water resources [11] [12]. It decreases the pressure on fresh water resources and wastewater treatment plants simultaneously. Domestic water use such as in kitchen, laundry, ablution and its commercial use (i.e. car wash) produce a large quantity of greywater on daily basis. The average per capita use of water is 80-100 gallons per day and almost $60 \%$ of wastewater available in the form of grey water. Potential of different places for water reuse have already been discussed in many studies [13]. It can be reused through a cheaper and relatively simple treatment. Hence a lab scale greywater filtration plant was fabricated and some physicochemical characteristics such as total suspended solids (TSS), total dissolved solids (TDS), turbidity, $\mathrm{pH}$, hardness and oil/grease concentration have been checked and results were found in permissible limits after filtration and disinfection.

\section{MATERIAL AND METHODS}

A pilot plant has been designed which consists of two segments containing a $0.25 \mathrm{HP}$ pump, sand filter, carbon filter, sedimentation tank and filtered water storage tank. The water samples from laundry, kitchen, and car washing stations were collected in the sedimentation tank. Initially the suspended particles were allowed to settle down through sedimentation and flocculation.

Journal of Applied and Emerging Sciences Vol (10), Issue (01)

\section{A. Filtration}

Wastewater from sedimentation tank was pumped through 10 inches thick sand filter with an optimum flowrate of $170 \mathrm{lit} / \mathrm{hr}$. The sand filter was composed of sand and gravels of different sizes. The filter was filled with four layers of different filtration materials, of which, the top and bottom were being filled with gravels and the second and third layers were composed of coarse and fine sand particles, respectively. After passing through the gravel and sand filter, the water sample was passed through carbon filter by gravity. Carbon filter was also comprises of three layers i.e. top and bottom layers were composed of coarse activated carbon granules while the middle one consists of fine granules. Filtered water sample was collected in the storage tank after being passed through UV light for disinfection. Overall process consists of two major filtration sections clearly shown in Figure 1.



Figure 1Grey water Filtration Plant

\section{B. Backwashing}


The major advantage of current research is the presence of backwashing mechanism in it for filter media. This will increase the life of filter by cleaning filter media on the spot. The concurrent beds are backwashed to relieve compression and remove particulate matter (often called "fines") [11][16]. Valves were designed and installed in such a sequence that during filtration only V-2, V-3, V-10 and V-11 were remain opened and rest of the valves were kept closed, while during backwashing V-1, V-4, V-5 and V-7 were kept opened by keeping all other valves closed. V-6 and V-8 were used as discharge valves during backwashing. Also, sludge from sedimentation tank can be removed during backwashing by opening $\mathrm{V}-1$ and V-9. The flow chart is given in Figure 2.



Figure 2Process flowchart

\section{RESULTS AND DISCUSSIONS}

In current study, six parameters have been tested and found a considerable difference in the results after filtration; where, all parameters were found to be within the allowable limits as shown in Table 1. The highest removal efficiency observed was in terms of turbidity, where, the analyzed turbidity of greywater sample was 253 NTU which was after filtration reduced to 3.7 NTU with a removal of $98.53 \%$. The removal of TSS, TDS, Hardness and Oil were calculated to be $80 \%, 67.69 \%, 62.68 \%$ and $51.85 \%$, respectively. The $\mathrm{pH}$ of the water sample after filtration was recorded to be 8.6 which was 6.9 before the filtration process. The $\mathrm{pH}$ moved to alkaline due to the removal of some acidic components from the greywater [17]. The limit of $\mathrm{pH}$ is although near the upper allowable limit but it is feasible to be used for the domestic applications i.e., agriculture, service stations or cleaning etc. However, the limits of each contaminants should be taken into account according to the end use.

Table 1Results before and after filtration of samples taken from residential area of Baleli, Quetta, Pakistan

\begin{tabular}{|c|c|c|}
\hline Parameters & Before filtration & After filtration \\
\hline TSS & $1000 \mathrm{mg} / \mathrm{l}$ & $200 \mathrm{mg} / \mathrm{l}$ \\
\hline TDS & $590.9 \mathrm{mg} / \mathrm{l}$ & $400 \mathrm{mg} / \mathrm{l}$ \\
\hline Turbidity & $253 \mathrm{NTU}$ & $3.7 \mathrm{NTU}$ \\
\hline $\mathrm{pH}$ & 6.9 & 8.6 \\
\hline Hardness & $321.6 \mathrm{mg} / 1$ & $120 \mathrm{mg} / 1$ \\
\hline oil & $27 \mathrm{mg} / \mathrm{l}$ & $14 \mathrm{mg} / \mathrm{l}$ \\
\hline
\end{tabular}

\section{A. Parameters Calculation}

Standard methods have been followed for calculation of TSS, TDS, turbidity, $\mathrm{pH}$, hardness and oil in water samples before and after the treatment [5] [6] [15] [16]. TDS, $\mathrm{pH}$, and turbidity of the samples have been checked by using portable TDS, $\mathrm{pH}$, and turbidity meter from Mettler Toledo before and after filtration available at Central laboratories of Faculty of Engineering, Balochistan University of Information Technology, Engineering and Management Sciences, Quetta, Pakistan. However, TSS was calculated manually by weight method using following equation at Chemistry lab, BUITEMS.

TSS $=\{$ Final weight - Original weight $\} * 1,000,000 /$

\section{Sample volume}

For TSS calculation, Whatman 42 filter paper was used to calculate TSS in the sample. The filter paper 
was placed on the funnel and the filtrate was collected inside the beaker placed at the bottom of the funnel. 10 $\mathrm{mL}$ of sample after being agitated was poured evenly on to the top of filter paper. Vacuum was created inside the beaker so that the water sample can pass quickly through the filter paper. After filtration, the vacuum was turned off and filter paper was removed and placed in Petri dish. The dish was then placed in an oven and heated for 3 hours at $105^{\circ} \mathrm{C}$. After 3 hours the sample was kept in desiccator for 30 minutes, where it cooled in a moisture free environment. Afterwards the weight of the sample was calculated.

The main objective of plant was to check the filtration capacity and treated water quality for reuse. The removal efficiency of each parameter was calculated based on its concentration before and after the filtration process and the results are shown in Figure 3. The removal of the contaminants were compared with the similar kind of filtration system designed by [12], in which the authors were successful to remove

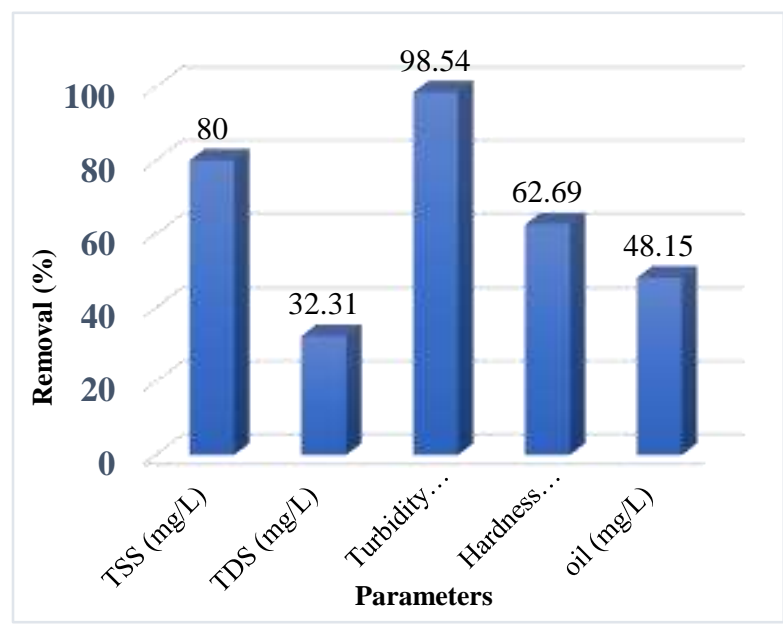

Figure 3 Removal efficiency of the Lab Scale Greywater Filtration Plant

BOD, COD, and TSS up to 49, 51, and $76 \%$, respectively. The removal efficiency of current study was found higher when compared to the above results with modified and effective technique of filtration being used.

\section{CONCLUSIONS}

The pilot filtration plant provides a low cost and easy technique of treating domestic grey water for irrigation, car washing and other sanitary works. This is one of the best alternatives in water stressed areas. The removal efficiency of turbidity, TDS, TSS, total hardness, and oil were calculated to be $98.54,32.31$, $80,62.69$, and $48.15 \%$, respectively. The technical adjustment of the valve positions had reduced the number of pumps being installed which ultimately had reduced the manufacturing cost and made the process very simple. Also, all results are in allowable limits, which is recommended to install on commercial scale to manage water resources positively. Further, a little variation in filter media can increase the reduction in contaminants.

\section{ACKNOWLEDGEMENT}

Authors would like to thank Department of Chemical Engineering, Balochistan University of Information Technology, Engineering and Management Sciences (BUITEMS), Quetta for providing laboratory facilities and to provide space for designing this lab scale plant. We, also would like to thanks to Faculty of Environmental Management, Prince of Songkla University (PSU), Hatyai Campus for providing work station to complete this manuscript. Authors didn't get any specific funding for this research from any funding agency/institution.

\section{REFERENCES}

[1] P. B. of Statistics, "DISTRICT AND TEHSIL LEVEL POPULATION SUMMARY WITH REGION BREAKUP." [Online]. Available: http://www.pbs.gov.pk/sites/default/files/bwp sr/balochistan/QUETTA_SUMMARY.pdf. 
[Accessed: 26-Jul-2019].

[2] S. M. Khair, S. Mushtaq, R. J. Culas, and M. Hafeez, "Groundwater markets under the water scarcity and declining watertable conditions: The upland Balochistan Region of Pakistan," Agric. Syst., vol. 107, pp. 2132, 2012.

[3] T. Ali, W. Ali, and Shahnaz, "Water Scarcity and Social Well-being of People in Makran," Indian J. Public Adm., pp. 1-8, 2019.

[4] A. S. Khan, S. D. Khan, and D. M. Kakar, "Land subsidence and declining water resources in Quetta Valley, Pakistan," Environ. Earth Sci., vol. 70, no. 6, pp. 27192727, 2013.

[5] B. L. Pangarkar and S. B. Parjane, "Design and economical performance of gray water treatment plant in rural region," World Acad. Sci. Eng. Technol., vol. 37, no. 1, pp. 896900, 2010.

[6] I. Zahid et al., "MUNICIPAL WASTEWATER TREATMENT USING RICE HUSK AND KIKAR," in nternational Research Symposium on Engineering Advancements 2016 (IRSEA 2016) SAITM, Malabe, Sri Lanka, 2016, no. June, pp. 5659.

[7] Asadullah; et al., "Removal of Zinc ( II ) from municipal wastewater using chemically modified activated carbon developed from Rice husk and Kikar charcoal," J. Apllied Emerg. Sci., vol. 09, no. 1, pp. 41-47, 2019.

[8] Z. N. Qaisrani;, Asadullah;, M. Hashim;, S. K. Sami;, S. H. Sultan;, and M. Siddique, "Desalination of Seawater Using Lab Scale Solar Plant," J. Appl. Emerg. Sci., vol. 09, no. 1, pp. 63-67, 2019.

[9] M. H. Nawaz; and M. A. Baig, "Domestic three stage water-treatment option for harvested rainwater in water-stressed communities Domestic three stage watertreatment option for harvested rainwater in water-stressed communities," IOP Conf. Ser. Sci. Eng., vol. 414, p. 6, 2018.

[10] J. Hoslett et al., "Surface water filtration using granular media and membranes: A review," Sci. Total Environ., vol. 639, pp. 1268-1282, 2018.
[11] B. Maryam and H. Büyükgüngör, "Wastewater reclamation and reuse trends in Turkey: Opportunities and challenges," $J$. Water Process Eng., vol. 30, no. October, p. 15, 2019.

[12] I. W. A. Publishing and W. Science, "Greywater treatment by granular fi ltration system using volcanic tuff and gravel media Abeer Albalawneh, Tsun-Kuo Chang and Heba Alshawabkeh," no. November, pp. 2331-2341, 2018.

[13] L. C. C. da Silva, D. O. Filho, I. R. Silva, A. C. V. e. Pinto, and P. N. Vaz, "Water sustainability potential in a university building - Case study," Sustain. Cities Soc., vol. 47, no. January, p. 101489, 2019.

[14] M. L. Davis, Water and wastewater engineering: Design principles and practice, Profession. WefPress for the water quality professionals, 2011.

[15] E. Worch, Adsorption Technology in Water Treatment: Fundamentals, Processes, and Modeling. 2012.

[16] F. Yang, S. Zhang, Y. Sun, K. Cheng, J. Li, and D. C. W. Tsang, "Fabrication and characterization of hydrophilic corn stalk biochar-supported nanoscale zero-valent iron composites for efficient metal removal," Bioresour. Technol., vol. 265, pp. 490-497, 2018.

[17] C. C. Nnaji, C. N. Mama, A. Ekwueme, and T. Utsev, "Feasibility of a FiltrationAdsorption Grey Water Treatment System for Developing Countries," pp. 1-6, 2013.

[18] A. B. Dichiara, S. Weinstein, and R. E. Rogers, "On the Choice of Batch or FixedBed Adsorption Processes for Wastewater Treatment," 2015.

[19] F. . Rainwater and L. . Thatcher, "Methods for Collection and Analysis of Water Samples," 1968.

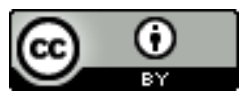

Journal of Applied and Emerging
Sciences by BUITEMS is licensed under a Creative
Commons Attribution 4.0 International License.

